\title{
Quem são as crianças que estão nas ruas: vítimas ou vitimizadoras?
}

\author{
Simone dos Santos Paludo \\ Silvia Helena Koller \\ Universidade Federal do Rio Grande do Sul
}

\begin{abstract}
RESUMO
A vida na rua é permeada por fatores de risco para o desenvolvimento saudável, tais como violência, ausência de adultos e cuidadores, drogas e perigos. Esses são desafios constantes e tornam essa população extremamente vulnerável. A exposição e o testemunho diário de situações de risco pode ter um impacto negativo em todas as pessoas, principalmente nas crianças que vivem no contexto da rua. Portanto questiona-se como a rua pode modificar o desenvolvimento dessa população. Este estudo investigou o impacto que a violência e o ambiente da rua podem assumir nas vidas destas. Verificou a percepção dos processos de vitimização e os diferentes papéis que estas crianças podem assumir: vítimas, agressores ou testemunhas. Foram utilizados uma entrevista semi-estruturada e aplicado um instrumento projetivo, denominado SCAN BULLYING - "Scripted-Cartoon Narrative of Bullying". Dentre os principais resultados destaca-se a transição e a assunção dos diferentes papéis. Todos os participantes identificaram em suas trajetórias pessoais o papel de vítima e, ao mesmo tempo 59\% relataram a assunção do papel de testemunha e agressor em situações de vitimização. Constatou-se que a sociedade, a cultura e os estereótipos incrementam o impacto da violência na vida diária e, conseqüentemente, as possibilidades de diversificar papéis no contexto da rua.
\end{abstract}

Palavras-chave: situação de rua; vitimização; violência.

\begin{abstract}
Who are the street children: victims or bullies?

Life in the street is permeated by risk factors, such as violence, adult caregivers absence, drugs, dangers. These are constant challenges turning this population extremely vulnerable. The exposition to daily risky situations can have a negative impact on the population, specially on street children. Therefore the effect of street life on these children is discussed. This study investigated the impact that violence and street environment could represent in their lives and verified the victimization perception and different roles assumed by these children: victims, bullies or witnesses. A semi-structured interview was used and the psychological instrument "SCAN BULLYING - Scripted-Cartoon Narrative of Bullying" was applied. The transition and assumption of different roles is emphasized in the results. All participants identified in their personal lives the role of victim, concurring to the assumption of witness and bully roles in victimization situations by $59 \%$ of them. It was verified that society, culture and stereotypes increase the violence impact in their daily life and, consequently, promote different roles in the street environment.
\end{abstract}

Keywords: street child; victimization; violence.

É comum encontrarmos crianças e adolescentes vagando pelas ruas, pedindo esmolas, limpando carros, usando drogas e até trabalhando nos faróis das cidades, embora, muitas vezes, não percebamos a presença deles, pois já fazem parte do cenário cotidiano. Mas, quem são essas crianças? o que fazem ali? e por que estão nas ruas? Encontrar uma única resposta para essas perguntas tem sido uma tarefa difícil para os pesquisadores. A literatura tem gerado muitas definições sobre quem são, como são e quantos são as crianças e adolescentes em situação de risco, que estão se desenvolvendo nas ruas da nossa cidade e do mundo. No entanto, é impossível "rotulá-los" como pertencentes a grupos estáticos, como meninos(as) de rua ou meninos(as) $\boldsymbol{n} \boldsymbol{a}$ rua. Segundo Koller e Hutz (1996), a terminologia crianças em situação de rua é a mais adequada, pois essa população é bastante heterogênea e utiliza o espaço da rua em diferentes momentos e com objetivos diversos. Alguns indicadores básicos são utilizados para caracterizar a relação que crianças e adolescentes estabelecem com a rua (Alves, 1998; Aptekar, 1996; Forster, Barros, Tannhauser \& Tannhauser, 1992; Hutz \& Koller, 1999; Martins, 1996). Recentemente, foi proposta uma classificação a partir de cinco parâmetros: a vinculação com a família; a atividade exercida; a aparência; o local em que se encontra a criança ou o adolescente e a ausência de um adulto responsável junto à mesma (Neiva-Silva \& Koller, 2002). Paludo e Koller (2004) sugerem, ainda, o horário como um importante facilitador na identificação. Estes indicadores permitem uma definição mais acurada do que a literatura 
que os caracteriza como meninos(as) de rua ou meninos(as) na rua.

Partindo de uma revisão histórica, percebemos que a descrição dessas crianças no senso comum foi se modificando, assim como a literatura científica sobre elas. Essas crianças já foram descritas como aberrantes, delinqüientes, drogadas, marginais, doentes, violentas, sujas, entre outras representações carregadas de valores negativos (Alves, 2002; Koller \& Hutz, 1996). Inicialmente, os estudos enfatizavam os déficits desenvolvimentais relacionados ao uso de drogas, promiscuidade, marginalidade, exclusão e desadaptação (Aneci Rosa, Borba \& Ebrahim, 1992; Aptekar, 1996; Campos \& cols., 1994; Carlini, 1990; Hutz \& Koller, 1996), os quais favoreciam uma imagem negativa a respeito desse grupo. Gradualmente, alguns estudos passaram a descrever as crianças em situação de rua como seres em desenvolvimento, que apresentam aspectos saudáveis frente a situações adversas (Aptekar, 1996; Koller \& Hutz, 1996; Swart-Kruger \& Donald, 1996). A partir desses estudos identificamse duas imagens possíveis para essa população: crianças vítimas e crianças agressoras. No entanto, faltam pesquisas sobre a percepção das próprias crianças e adolescentes em situação de rua a respeito do lugar que ocupam no ciclo da violência que sua condição os coloca.

A literatura aponta que essas crianças estão expostas a todo tipo de violência desde pequenas, e, muitas vezes, foram submetidas a diversos eventos de risco dentro de suas próprias casas (Cerqueira-Santos, 2004; Neiva-Silva, 2003; Paludo, 2004; Santana, 2003). A violência faz parte de suas vidas, tornou-se um hábito nunca questionado e, portanto, naturalizado no ambiente no qual estavam inseridas. Assim, a vida na rua muitas vezes representa a melhor alternativa encontrada pelas crianças que sofrem algum processo de vitimização, seja na família de origem ou na sociedade. Alguns pesquisadores procuraram entender as principais causas e motivações que provocam a saída destes de sua casa (Bandeira, Koller, Hutz \& Forster, 1996; Carpena, 1999; Koller \& Hutz, 1996). Entre estes, os problemas sociais, econômicos e afetivos são geralmente apontados como principais fatores que influenciam a saída para a rua. No entanto, gradualmente, a violência permeia também a vida no contexto da rua (Cerqueira-Santos, 2004; Neiva-Silva, 2003; Paludo, 2004; Santana, 2003). Outro aspecto importante refere-se à idade com que estas crianças iniciam o processo de afastamento das suas famílias. Estudos recentes apontam que a migração às ruas inicia aos cinco anos de idade em outros países (Aptekar, 1996; Verma, 1999). Esse é, com certeza, um dado assustador, pois essas crianças estão em idade pré escolar e não possuem maturidade cognitiva, emocional e física para sobreviverem sozinhas em um ambiente caracterizado por diversas situações de risco.

As crianças e adolescentes em situação de rua constituem o único grupo que cresce sem supervisão parental moral e afetiva estável e permanente. De modo geral, são caracterizadas como crianças maltratadas, vítimas de abuso e/ou negligenciadas, testemunhas da violência ou autores de infrações. Além disso, a vida cotidiana dessas crianças possibilita e, às vezes, até mesmo exige que leis e regras sejam transgredidas todos os dias. Assim, a rua, principal contexto de desenvolvimento dessa população, pode ser considerada como predispositor ao constante processo de vitimização e violência.

A violência pode ser definida de diversas formas, no entanto, de forma geral envolve uma ação que pode cessar, impedir, deter ou retardar o desenvolvimento pleno dos seres humanos (Koller \& De Antoni, 2004). Além disso, a violência ocorre em relações interpessoais assimétricas e hierárquicas, em que há uma desigualdade e/ou uma relação de subordinação. Existem diversos tipos de violência contra a criança e o adolescente, as formas mais comuns são o abuso físico, sexual, psicológico e a negligência. Garbarino, Kostelny e Dubrow (1991) afirmam que crianças expostas a qualquer forma de violência são modificadas por essa experiência, e os efeitos mais profundos acontecem no desenvolvimento psicossocial, moral, cognitivo e da personalidade. A exposição e o testemunho à violência podem ter um impacto negativo em todas as pessoas, principalmente nas crianças que estão mais vulneráveis.

Essa população está envolvida em um constante processo de vitimização e violência, o qual provoca a distribuição de papéis diversos em um grupo (Salmivalli, Lagerspetz, Bjorkqvist, Osterman \& Kauklainen, 1996). O papel de vítima é atribuído àquele indivíduo que tem pouca possibilidade de escapar de seus agressores. Já o papel de agressor é atribuído àquele indivíduo que provoca a situação e que, na maioria das vezes, recebe apoio dos seus companheiros de grupo para continuarem os ataques à vítima. E, finalmente, o papel de testemunha é atribuído àqueles que não participam ativamente do processo de vitimização, mas que, de alguma forma, estão envolvidos, ou conscientes do que está acontecendo. No entanto, a assunção dos papéis de vítima, agressor e testemunha não são excludentes e podem ocorrer de forma simultânea no cotidiano dessa população. Evidências empíricas mostram que os indivíduos vitimizados estão mais propensos a apresentarem problemas comportamentais e afetivos (Hodges, Boivin, Vitaro \& Bukowski, 1999).

Dessa forma, esse artigo pretende discutir os diferentes papéis assumidos pelas crianças e os adoles- 
centes em situação de rua a partir da sua própria percepção. Além disso, visa responder algumas questões intrigantes a respeito da influência e do impacto que a violência e o ambiente da rua podem assumir na vida dessa população. A exposição a diversos tipos de violência e a possibilidade de assumir diferentes papéis modificam o desenvolvimento das crianças em situação de rua? Como eles percebem esse processo de vitimização? Como se percebem: vítimas, agressores e testemunhas? A análise dos dados obtidos neste estudo busca encontrar algumas respostas a estas questões.

\section{MÉTODO}

Participantes: Este estudo foi desenvolvido com 17 crianças e adolescentes em situação de rua, com idades entre 11 e 16 anos $(M=14,05, D P=1,24)$, de ambos os sexos (29\% de meninas e $71 \%$ de meninos), identificadas por características exteriores, tais como aparência, vinculação com a família, atividade exercida, local em que se encontram e ausência de um adulto responsável junto à mesma (Neiva-Silva \& Koller, 2002).

Instrumentos e Procedimentos: Primeiramente, foi realizada uma entrevista semi-estruturada, com o objetivo de coletar dados bio-sócio-demográficos dos participantes, tais como, idade, sexo, experiência escolar e com o trabalho, local de moradia e lazer, e contato com a família. Foi feita a aplicação individual deste instrumento para que as respostas de um participante não influenciassem as respostas de outras crianças presentes. Devido à situação particular da rua e às próprias características dessa população, foi necessário que as pesquisadoras estivessem preparadas e treinadas para enfrentar as mais diversas situações e problemas que podem ocorrer durante a entrevista e a aplicação dos instrumentos (ver Paludo \& Koller, 2004). Esses podem ser identificados pela falta de interesse do entrevistado, o cansaço, a dificuldade de falar sobre assuntos mobilizadores, as interrupções de outros companheiros, entre outros. Embora a literatura ressalte que essas crianças valorizam o contato com adultos e pesquisadores e, geralmente, não recusam a sua participação (Hutz \& Koller, 1999). Após foi realizada a aplicação do instrumento psicológico Scripted-Cartoon Narrative Bullying - SCAN BULLYING (Almeida \& Del Barrio, 2002). Esse foi adaptado para o uso com crianças em situação de rua no Brasil (ver Paludo, 2004). Este apresenta uma história paradigmática de vitimização entre pares, que se desenvolve ao longo de dez cartões em que são representados vários subtipos de comportamentos de maltrato, após seguem-se outros cinco, que apresentam diferentes fins alternativos para a história. Especificamente, na linha da definição conceitual de vitimização, cada cena procura representar interações típicas de maltrato e, no conjunto, a história destaca o padrão consistente de abuso e desequilíbrio do poder. Os desenhos foram coloridos a fim de tornar o instrumento mais atrativo e lúdico para essa população e para facilitar o reconhecimento dos personagens e da continuidade da história. A entrevista consiste num conjunto de questões que se destinam a criar o contexto para a reflexão e os meios para aceder à compreensão social que as crianças manifestam acerca das relações de vitimização entre pares, especialmente as causas a que atribuem os comportamentos de vitimização, os sentimentos atribuídos aos agressores e às vítimas, as estratégias de confronto e a relevância dessas situações na vida pessoal dos participantes. Por último, é possível determinar a existência de experiências de maltrato e do tipo de participação ou papel do sujeito. Esta categorias procuram determinar o papel participante protagonizado pelo indivíduo. Este artigo discutirá apenas as questões relacionadas a essa última etapa do instrumento, a qual analisa o processo de vitimização na trajetória pessoal e identifica os papéis assumidos nessa situação.

Os estudos realizados com essa população possuem algumas particularidades em relação aos procedimentos de coleta de dados. Assim, o presente estudo baseou-se nas preocupações éticas e metodológicas discutidas nas recentes pesquisas envolvendo crianças e adolescentes em situação de rua do Centro de Estudos Psicológicos de Meninos e Meninas de Rua (Alves, 2002; Cecconello \& Koller, 2003; Hutz \& Koller, 1999). Uma importante colaboração da Resolução $\mathrm{n}^{\circ} 16$ (CFP, 2000) refere-se à pesquisa com as populações consideradas em situação de risco, uma vez que não exigem o consentimento livre e esclarecido de pais que não tenham contato sistemático com os seus filhos, guardiões legais que não tenham condições cognitivas para avaliar as conseqüências da participação das crianças na pesquisa e, ainda, pais ou guardiões que tenham abusado, negligenciado ou sido coniventes com o abuso de seus filhos.

Devido à complexidade que envolve a vida de crianças e adolescentes em situação de rua foi necessário realizar esta pesquisa no contexto da rua e em casas de acolhimento, locais onde esta população está se desenvolvendo. A proposta bioecológica de investigação por observação naturalística privilegia a inserção ecológica do pesquisador no ambiente a ser estudado (Bronfenbrenner, 1979/1996; Bronfenbrenner \& Morris, 1998). Para isto, a equipe de pesquisa se propôs a uma inserção no ambiente ecológico no qual estão esses meninos e meninas, com o objetivo de conhecer a sua realidade, acompanhando-os através de visitas freqüentes às casas de acolhimento, observações, conversas informais e entrevistas (Cecconello \& Koller, 2003). A inserção ecológica permitiu a aproximação tanto para os participantes quanto para os investigadores da pesquisa. A presença constante e 
significativa da equipe de investigadores possibilitou aos participantes, no momento da entrevista, contarem eventos de vida e, consequientemente, refletirem e aprenderem com eles. Em decorrência dessa interação a equipe pôde captar unidades de sentido importantes para responder às questões de pesquisa e desenvolver novas hipóteses teóricas. Segundo Cecconello e Koller (2003), a equipe precisa tornar-se parte do ambiente para adquirir a condição de inserida ecologicamente no contexto da pesquisa. Esse procedimento metodológico foi de extrema importância, uma vez que permitiu o engajamento direto das pesquisadoras no contexto das crianças e adolescentes, tanto na rua como nas instituições. Além disso, possibilitou uma maior confiança desses nas pesquisadoras, facilitando e garantindo confiabilidade e validade dos dados coletados (ver Paludo \& Koller, 2004).

\section{RESULTADOS}

A partir dos dados obtidos na entrevista semiestruturada foi feita uma análise de freqüência, a fim de realizar um levantamento das informações quantitativas para uma descrição mais acurada da amostra. Além disso, foi realizada uma análise qualitativa dos dados segundo o método de Bardin (1977/1979). Esta descrição é de extrema importância para a validação e a generalização dos estudos com crianças em situação de rua, uma vez que há uma impossibilidade de se obter uma amostra representativa desta população, devido à sua diversidade, dinâmica e a ausência de dados estatísticos absolutos (Aptekar, 1996).

Um primeiro aspecto a ser discutido refere-se à predominância de participantes do sexo masculino (71\%). Este dado corrobora a literatura existente sobre essa população, a qual aponta uma presença mais constante de meninos na rua (Aptekar, 1996; Martins, 1996a; Neiva-Silva; 2003; Raffaelli \& cols., 2000; Santana, 2003). Devido à inserção ecológica da equipe esse fato pôde ser observado, também dentro das casas de acolhimento. $\mathrm{O}$ número de meninas nesses locais também era reduzido, mas não inexistente. As meninas que participaram desse estudo representam $29 \%$, e foram encontradas apenas nas casas de acolhimento visitadas.

Outra importante questão refere-se à história anterior à inserção na rua. A trajetória da criança ou adolescente até chegar definitivamente a morar na rua passa por uma sucessão de fracassos ocorridos na sua interação com a família, parentes, amigos, escola, entre outros (Santana, 2003). Quando questionados sobre os motivos que os levaram à saída de suas casas, $12 \%$ dos entrevistados não quis informar sobre o evento ou a justificativa para sua migração para a rua. $\mathrm{O}$ fato de negarem a resposta a essa questão levanta a hipótese sobre a dificuldade de falar sobre assuntos relacionados, diretamente, aos vínculos afetivos e ao contexto familiar. Apenas $28 \%$ dos adolescentes mencionaram o sustento familiar como principal motivo de saída para a rua. É interessante salientar que essas respostas foram dadas pelas crianças que possuem vínculo efetivo com suas famílias $(n=5)$. Nesse caso, o espaço da rua é utilizado apenas para o trabalho " $E u$ estudo de manhã, e na quinta e sexta eu solto cedo, às 10hs. Daí eu venho para cá trabalhar. Aqui comecei com 12. Antes eu trabalhava assim de vender suco..." (F. E., 14 anos, sexo masculino).

Destacam-se as categorias "brigas familiares" e "iniciativa própria", especialmente relacionadas à fuga de casa, ambas representam $18 \%$ das respostas da população e envolvem, de maneira direta ou indireta, a violência doméstica. Estudos confirmam esse tipo de violência como um importante motivo para que as crianças abandonem suas casas (Aneci Rosa \& cols., 1992; Aptekar, 1996). A maioria ocorre dentro das próprias residências, tendo o principal agressor um parentesco com o abusado, seja esse pai, mãe, padrasto, madrasta, tio, entre outros. Esses atos foram cometidos por adultos que deveriam ser, a princípio, responsáveis pela segurança, proteção e supervisão da criança ou do adolescente.

As justificativas e motivações das brigas familiares são as mais diversas, no entanto, promovem a saída dos jovens de suas casas, "Morei, de 1 ano até os 3 com a mãe. Ai dos 3 até os 7 morei com o meu pai... Por causa que não deu certo com um nem com o outro, daí eu fugi de casa. Ah, meu pai bebia, batia daí eu peguei e fugi de casa, eu quis, não dava mais.., não gosto. Eu quis sair de lá” (E. M., 15 anos, sexo masculino).

Outro fator que merece consideração é a saída de casa devido a situações de abuso sexual. A violência sexual corresponde aos atos de natureza sexual impostos a uma criança ou adolescente por um adulto que explora seu poder, sob a forma de assédio verbal, invasão de limites corporais ou psicológicos através de toques ou palavras, e relações sexuais genitais, orais ou anais (De Antoni \& Koller, 2002). Esse tipo de violência pode ser encontrado nos relatos das meninas: "Eu saí de casa, por causa que quase fui estuprada pelo meu padrasto. Esses dias eu tava na cama ai ele pegou e passou a mão em mim, minha mãe foi trabalhar... Ele falava que se eu contasse para a minha mãe ele ia mandar as gurias me bater. Eu apanhava um monte, de várias gurias eu apanhava... daí eu saí de casa..." (C. A., 15 anos, sexo feminino).

Essa informação é corroborada em outros estudos que investigaram os motivos de saída para a rua (Bandeira \& cols., 1996; Koller, 1994). O uso de drogas $(6 \%)$ também foi indicado como um dos facilitadores para o abandono dos lares. Essas informações 
possibilitam identificar a assunção dos papéis de vítima e testemunha por parte das crianças e adolescentes no contexto de suas casas.

Em relação à experiência de trabalho na rua executados pelas crianças e adolescentes é importante ressaltar que as atividades foram aquelas que os próprios adolescentes definiram como trabalho. Quando questionados se faziam alguma atividade para conseguir ganho financeiro, $24 \%$ dos participantes mencionaram não desempenhar atividades de trabalho e $76 \%$ afirmaram exercer atividades que visam a obter recursos. De maneira semelhante à descrita na literatura (Martins, 1996), os dados demonstram que dentre as principais atividades encontram-se a guarda de automóveis nos estacionamentos e em vias públicas (31\%), mendicância (31\%), venda de alimentos (23\%), engraxate $(23 \%)$ e furtos $(15 \%)$. A atividade exercida como trabalho por meninos e meninas em situação de rua é uma das questões mais difíceis de ser discutida. $\mathrm{O}$ ambiente da rua proporciona diversas oportunidades de "ganhos financeiros", sejam esses lícitos ou ilícitos. Com certeza, esse é um dos principais atrativos para essa população preferir a rua a outros ambientes, como a escola e a própria casa. O dinheiro obtido com essas atividades é utilizado na aquisição de alimentos, lazer e drogas. Nessas situações, o papel de agressor torna-se mais evidente, como por exemplo, "Já roubei 285 reais... o cara estava com a carteira e eu passei. Eu não me arrependi, fiquei com o dinheiro para mim. Ô meu, demorei cinco dias para gastar o dinheiro. Comprei um monte de coisas, era cachorroquente, era pipoca, era... joguei videogame, aluguei uma moto, fiz o escambal!!! Comprei baseado, loló... fizfesta...!!!” (J. A., 13 anos, sexo masculino).

A partir dessas informações, pode-se constatar a presença constante do processo de vitimização contra os jovens e a emergência de diferentes papéis, uma vez que testemunham e/ou participam de forma voluntária ou não de atos de violência na sua comunidade e na própria família. Os episódios de vitimização na trajetória pessoal dos participantes foram investigados através da aplicação do Scan Bullying. Cabe ressaltar que o instrumento psicológico Scan Bullying facilitou e promoveu a comunicação entre o participante e as pesquisadoras na expressão de emoções difíceis de serem verbalizadas. A sua aplicação consistia em um momento lúdico de descontração e criatividade para os participantes, além de promover a confiança do entrevistado, ao sentir-se acolhido e escutado. As histórias que contavam de um menino ou menina fictício eram permeadas de eventos vividos pelos mesmos. Naquele momento compartilhavam suas histórias, seus medos e tragédias identificados com o protagonista. De uma maneira geral, os relatos de eventos de vida foram permeados de situações de vitimização. Podem ser destacados eventos envolven- do conteúdos sobre violência doméstica, participação em gangues, abusos sexuais, uso abusivo de drogas, envolvimento em mortes e até tentativa de suicídio. Esses eventos dão a dimensão da "subcultura" ou cultura da rua. Este espaço propiciou a expressão de diversas emoções, tanto por parte dos participantes como por parte das pesquisadoras. E, ao mesmo tempo, foi essencial para o entendimento do contexto em que vivem essas crianças e adolescentes.

Neste artigo, serão apresentados e discutidos apenas os resultados referentes à última parte da aplicação desse instrumento, os quais referem-se de forma específica aos papéis assumidos em situações de violência e vitimização. Após relatarem uma história fictícia sobre os personagens das lâminas, as crianças e os adolescentes foram convidados a relatar eventos pessoais através da pergunta: "Já aconteceu algum fato parecido com o que se passa nessa história? Gostarias de falar sobre isso?".

A partir dos relatos sobre eventos pessoais foi feita uma análise de conteúdo das respostas (Bardin, 1979), referentes à última questão do instrumento. Essa possibilitou categorizar o papel que assumiam frente a situações de vitimização. As categorias determinaram o papel do participante protagonizado pelo indivíduo, quer como agressor, testemunha e/ou vítima. Como a assunção dos papéis de vítima, agressor e testemunha não são excludentes, foram encontradas mais de uma resposta por parte dos entrevistados sobre a participação no eventos de vitimização.

Cem por cento dos participantes identificaram-se com o papel de vítima. Os principais eventos de vitimização referem-se a episódios na escola, em casa e nas ruas. $\mathrm{O}$ ambiente da escola foi apontado como principal sistema no qual ocorrem episódios de vitimização, seja na entrada diária ou no primeiro dia de aula. Os relatos indicam preocupação com a aceitação em um novo ambiente, ainda desconhecido por eles, como por exemplo: "Senti vergonha, porque sou novo no colégio" (E. L., 14 anos, sexo masculino). Um outro menino, de 14 anos, contou como foi recebido na escola nova: "Eles falaram que eu era aluno novo, $e$ os alunos novos apanhavam". A vitimização na escola pode ocorrer, também, quando o aluno já está integrado nesse ambiente e com seus colegas. $\mathrm{O}$ adolescente E. D., 12 anos, relatou o seguinte evento: "Eles (colegas) esconderam o meu material. Eu sabia que alguém estava escondendo de arreganha. Fiquei triste... eu nem sei explicar. Fui lá contar para professora, eu perguntei para eles e eles disseram que não foram eles daí quando a professora foi lá disse que se o material não aparecesse ninguém ia sair. Quando vi eles acharam".

Outro sistema indicado pelos participantes como propício para sofrerem episódios de vitimização foi a 
própria casa e, na maioria das vezes, os abusadores eram os próprios familiares. A menina V. A., de 13 anos, relata: "Ela (mãe) que me mandou sair de casa, eu não queria sair de casa. Por causa que ela disse que eu dava muita confusão para ela por causa do conselho tutelar. Me mandou embora de casa, disse que não queria ver mais em casa, nem me ver mais lá. Não sei me deu uma coisa assim, eu não conseguia mais falar. Não sei, comecei a chorar. Senti um aperto. Eu não queria ficar longe dos meus irmãos, não queira ficar longe da minha mãe. Do meu padrasto eu queria ficar longe porque ele me maltratava muito. Bate com alguma coisa, vela de pau, ela me batia com tudo o que tem pela frente".

Esse dado corrobora estudos sobre a violência, que apontam a ocorrência de maltrato dentro dos ambientes domésticos. Segundo De Antoni e Koller (2002), em mais da metade dos casos envolvendo episódios violentos, o agressor tem parentesco com o abusado. Ainda, na maioria das vezes, as vítimas são meninas e o abusador apontado com maior incidência é o pai. No entanto, quando essas crianças e adolescentes saem desse ambiente para o contexto da rua acreditam que estão "livres" de situações semelhantes. A rua, a princípio, oferece a "liberdade" e a dimensão lúdica que, aos poucos, vai dando lugar às experiências dolorosas da violência física, sexual e moral. O adolescente G. L. (15 anos) relata: "Na primeira semana (na rua) eu fui roubado. Tentaram me botar fogo, botaram álcool em cima da minha blusa, assim, e queimou a blusa. A blusa eu recém tinha comprado, também, daí ficou um buraquinho assim, eu tive que tocar fora a blusa. Não que eu senti um pouquinho assim, daí estava encostada na barriga, ai eu senti um pouquinho do calor assim e puxei a camisa assim, quase me queimou todo... Eu não vi estava dormindo em cima de uma árvore. Eu gosto de ficar em cima da árvore. Lá em Viamão tem. Não é ficar pendurado, é deitar embaixo da árvore.... (risos)".

Os relatos dos participantes revelam que a violência e a vitimização esteve e está presente em todos os contextos nos quais essa população está inserida. Esse é um dado preocupante, uma vez que as famílias e as escolas deveriam exercer um papel protetivo na vida de qualquer ser humano. Em vista disso, é importante e fundamental que a sociedade, as instituições e a escola ofereçam atenção imediata a esse problema social, a fim de resgatar os vínculos afetivos e o comprometimento com a vida. Além disso, esses dados sugerem a importância da criação de medidas preventivas com base em dados científicos, abordando desde as famílias de origem até a sociedade em geral.

Dessa forma, a constante vitimização desses adolescentes possibilita que não reconheçam ou não acreditem em suas potencialidades, tornando-os ainda mais vulneráveis à violência e possibilitando a assun- ção do papel de agressor. Nesse estudo, a partir das falas sobre os eventos de vida, pode-se constatar que $59 \%$ dessa população $(N=17)$ já assumiram o papel de agressor em algum momento da sua trajetória. Os ambientes apontados como eliciadores dessas transgressões, também, foram a casa, a escola e a rua. $\mathrm{O}$ relato do menino R. A. (15 anos) demonstra como assumiu o papel de agressor, após um episódio de vitimização na escola: "Eu fui pra outro colégio, eu comecei a fazer a quinta série. Não gostei, porque meu pai já tem mais dinheiro que a minha mãe, né, aí ele me colocou num colégio, lá no IAPI, só coleginho de mauricinho... são muito cheio. Aí uma vez eu impliquei no colégio e me expulsaram, dai eu fui para casa da minha avó. O professor de educação física tinha falado para nós fazer, fingir que estava lutando, que nós ia fazer uma apresentação, quando vê sem querer o guri caiu, e todo mundo começou a rir dele. Daí ele veio querer brigar comigo, daí eu peguei, bati nele. Ele me deu um soco na cara e eu dei nele. É, bem dizer não fui expulso, só mandaram uma carta para o meи pai, mas eu não quis mais estudar".

A vida na rua expõe esses adolescentes a todo tipo de risco e, às vezes, o papel de agressor é utilizado como uma estratégia de sobrevivência, como por exemplo, brigas entre companheiros ou grupos, defesa pessoal, entre outros. No relato de E. M., de 15 anos, este indicou diversos eventos nos quais ele assume esses papéis. Primeiramente, pode-se constatar o papel de agressor durante alguns anos de sua vida, conforme seu relato: "Eu assinei 1.12, que é traficante. Daí depois eu peguei assinei um 1.57, assalto à mão armada. Daí depois eu caí por 1.55, que é arrombamento. Ai depois eu caí de novo repetindo. Por um 1.12, 1.57, 1.55. Foi ruim... Fiquei seis meses da primeira vez, na segunda vez eu fiquei um ano, e na terceira vez eu fiquei um ano e meio, na quarta vez daí já não tinha muita coisa daí me deixaram mais um ano e meio, daí a quinta vez eu peguei e fiquei um ano de novo, só que daí eu fui eu mudei da Febem para uma mais fechada. Daí depois na sexta vez eu fui para o CJPOA e fiquei dois anos". Esse é um dado assustador, considerando que o menino possui apenas 15 anos e durante quase sete anos está envolvido em crimes, ou seja, sua saída para rua aconteceu quando tinha apenas oito anos e, desde essa idade, já está participando de gangues e compartilhando de eventos violentos. Cabe ressaltar que esse relato indica um "falso testemunho" do menino, mesmo assim faz parte da vivência cotidiana dele. Devido às prescrições do Estatuto da Criança e do Adolescente (ECA), o art. 104 afirma "são penalmente inimputáveis os menores de dezoito anos, sujeitos às medidas previstas nesta lei". Dessa forma, pode-se confirmar que o adolescente E. M. não foi preso conforme relatou, pois tem apenas 15 anos. No entanto, seu relato não pode ser 
desqualificado, ou ainda, apontado como falso ou verdadeiro. Koller (1994) sugere não julgar as respostas dos participantes, mas identificar as capacidades dessas crianças e adolescentes para elaborar e emitir histórias, sejam essas permeadas de fantasias ou não. As informações trazidas pelo menino sobre os assaltos, a participação no tráfico e sua ida para Febem foram confirmadas pelos monitores da casa. Durante esses eventos característicos da população de rua, o último adolescente citado (E. M.), participou, simultaneamente, como testemunha e agressor de uma briga entre as gangues que tirou a vida de sua namorada: "Foi por causa de uma briga de gangue lá do meu primo, lá. Os caras chegaram lá estacionaram na frente da casa dele e começaram a fumar maconha. Daí ele pegou, chegou lá na rua e falou: pô, meu, não dá para vocês darem licença aí, depois chegam os homem (polícia) e suja para mim e para vocês. Daî eles vão pensar que eu sou traficante ou não sei o quê! Ou que eu ando fornecendo para vocês. Daí os guris não quiseram sair, daí meu primo foi lá dentro e pegou o 32 dele colocou na cintura, daí os guris viram o volume e já começaram a puxar os armamento. Daí quando vê assim, os caras pegaram e apontaram para o meu primo, daí o meu primo pegou e pихои a arma da cintura, daí nisso estão chegando os amigos dele já, já começaram a puxar arma e começaram a trocar tiro. Daí ele disse: vai lá cara e pega a 12 que tá debaixo da cama, aquela dos dois canos, aí eu pensei tá, daí eu fui lá e peguei, daí eu fiquei com a 32 e eu dei a 12 para ele, assim, daí a gente começou a trocar tiro, daí bem na hora ela (namorada) saiu na porta, assim, daí o cara pegou e deu dois tiros assim no peito dela".

Outro evento relatado pelo mesmo menino o identifica como a vítima da situação de violência: "Não foi uns contra lá que estavam dentro da Febem, eu cheguei lá sozinho lá, daí só tinha dois amigos meus, e eu não vi que no "bret" (quarto) 15 tinha uns contra meu, né. Daí quando vê me puxaram lá pra dentro do prédio 15, só eu e os contra. Daí eles pegaram e me deram um pauzão lá dentro. Eles amassaram duas, três marmitas junto, daí aquilo ali é alumínio, daí a ponta corta. Daí dois me seguraram, daí pegaram assim os lençóis começaram a me amarrar, colocaram o lençol na minha boca para eu não gritar, $e$ começaram a rasgar a minha perna. E cabeça, as coxas, tudo rasgado... Daí depois apareceu um monitor e viu que eu estava sangrando, pegou e colocou os guris tudo lá para o isolamento". Os relatos desse menino constatam a possibilidade de assunção de diferentes papéis, seja em diferentes contextos ou em uma única situação. É importante salientar essa característica de "mutação" dos papéis de agressor, vítima e testemunha a fim de facilitar a compreensão dessa população. Os estereótipos cristalizam e ofere- cem apenas imagens extremas: ora coitadinhos, ora delinquientes. No entanto, crianças e adolescentes em situação de rua são seres humanos em desenvolvimento, que apresentam aspectos saudáveis e deficitários. Além disso, a assunção de diferentes papéis quando frente a situações de risco ocorre com todas as pessoas. A dinâmica do contexto da rua favorece a emergência simultânea da vítima, do agressor e da testemunha, uma vez que a violência, o crime, o medo, tornam-se estratégias de sobrevivência.

O papel de testemunha foi indicado, também, em $59 \%$ dos relatos dos participantes. Foram considerados testemunhas todos os relatos que continham a participação desses meninos e meninas, como observadores e/ou ouvintes, em episódios de transgressão. A maioria dos relatos indica a participação passiva nos eventos de violência doméstica, tiroteios, mortes, entre outros. No relato do menino S. A., 11 anos, pôde ser observado o papel de testemunha da violência doméstica que assistiu quando seus pais moravam juntos: "Eles brigavam. Minha mãe se separou dele, por causa que ele vai sempre bêbado lá. Ela bate de facão nele. Eu vejo, depois eu saio".

$\mathrm{O}$ relato da V. A. (13 anos) aponta a mesma problemática dentro da própria casa, quando morava lá e, ainda, a omissão das pessoas que convivem na mesma comunidade: "Ele pegava e botava a arma na cabeça da minha mãe, falava um montão de coisa, dizia que ia matar todos em casa. Eu começava a chorar, gritar e espernear. Ninguém ia ajudar em casa, os vizinhos ficavam tudo ali na frente olhando, mas ninguém ia ajudar. As pessoas olhavam e não faziam nada. Que raiva deles! Eles ficavam lá na frente da minha casa, todo mundo parado, só olhando. Se eu tivesse uma arma dava um tiro bem no meio da cabeça dele. Ele chegava em casa chapado, ia lá chapado de loló, chapado de pedra. Batia mais em mim e na minha mãe".

A rua, também, foi indicada pelos participantes como um local de risco, onde podem ser observados diversos eventos violentos. A participação como testemunha em situações ocorridas, tanto no ambiente da rua como no abrigo, pode ser constatada no seguinte relato: "A P. A. é uma grandona, assim ela é uma baita dum mulherão, bem maior que a gente e a guria, nós erámos lá do abrigo, daí a gente sempre brincava junto. Mas um dia ela pegou e pediu para as gurias segurarem a C. A. e enfiou um cabo de vassoura e daí a guria saiu assim toda sangrando, pegou foi para o médico, levou até ponto. Bem pequeninha ela era... Daí, depois de uma semana, não deu dois meses eu acho, ela queria fugir, ela falou que não queria mais falar com ela (P. A.), daí eu peguei e fugimos assim, fomos para a rua. Daí nós se encontramos tudo ali no gasômetro, e a P. A. estava tomando banho né, daí ela (C. A.) pegou e disse que queria entrar dai eu peguei 
e entrei com ela. Só que estava eu, ela, as gurias. A $P$. A. já era uma baita duma guria, nós era bem pequenininha. Quando a C. A. gritou que não dava mais pé, era muito fundo, só que eu não tinha mais como ajudar ela porque eu também estava quase morrendo, assim também. Depois eu falei: $\hat{O}, P$. A., tu que é maior, ajuda nós aqui, oh, P. A., oh, P. A.! Fiquei chamando ela! Daí ela me olhou para mim e disse o problema é de vocês, daí eu comecei a gritar: aí, coitadinha da C. A., daí eu pedi ajuda, daí a A. N. me puxava, não a K. E. puxava a A. N., a A. N. me puxava e eu tentava puxar a C. A. Mas daí quando eu vi a C. A. escapou da minha mão. Eu pedi para P. A. me ajudar, vem aqui para pegar a outra mão da C. A., e ela disse: por mim que morra afogada. Daí quando ela disse isso a mão da guria soltou e ela ficou no rio. Morreu afogada" (A. N., 14 anos, sexo feminino).

Esses relatos identificam a presença constante dos fatores de risco que estão envolvidos no cotidiano da rua desses meninos e meninas. Cerqueira-Santos (2004), também, identificou situações adversas no cotidiano dessas crianças. As próprias crianças e adolescentes em situação de rua confirmaram esse ambiente como um local inadequado para viverem e se desenvolverem: "Me sinto assim, estranha, porque eu queria estar em casa, sabe... rejeitada. É tinha vezes que tinham que me segurar porque eu me cortava com caco de vidro, me cortava toda com caco de vidro, me machucava aqui olha! (mostra as marcas pelo corpo). Eu quero mas as tias não deixam, já tomei uns vidrinhos assim, sabe uns remédios, veneno já tomei já. Eu penso porque que eu não morri, só nisso que eu penso. Eu fico pensando, queria ser como as outras pessoas, assim não ter passado por nada disso, não estar na rua, estar em casa, ter onde dormir, ter onde ficar (V. A., 13 anos, sexo feminino)".

Outros estudos enfatizam a ocorrência de tentativas de suicídio nessa população (ver Brito \& cols., 1998; Noto, Galduróz, Nappo, Fonseca, Carlini, Moura \& Carlini, 2003). Essa estratégia de enfrentamento alternativo revela ausência de recursos internos e externos dessa população para lidar com o cotidiano. Os principais motivos apontados nas tentativas de suicídio estão relacionados com as condições de vida e a insatisfação com os relacionamentos afetivos. A deficiência de reciprocidade, afeto e equilíbrio de poder nas relações interpessoais refletem a miséria afetiva no cotidiano desses meninos e meninas. Outros relatos indicam, ainda, a falta de perspectiva e as expressões emocionais que encontram e que permeiam o ambiente da rua: "Triste eu sou. Nunca vou ser alegre. Porque eu, porque nunca aconteceu nada de bom pra mim rir" (T. I., 14 anos, sexo masculino). A partir da inserção ecológica pode-se constatar uma tendência desses meninos e meninas a apresentarem sentimentos de rejeição e de abandono, além de pobreza afetiva, evidenciada pela falta de empatia e trocas de carinho. Nesse sentindo, o contexto da rua torna-se uma ameaça à saúde psicológica.

Outro fator de risco apontado nas respostas dos participantes foi a droga. O consumo de drogas está intimamente ligado ao modo de vida e às estratégias de sobrevivência. A prevalência de uso é significativa entre os participantes desse estudo, uma vez que $65 \%$ afirmaram utilizar drogas, ressaltando o uso de loló. Esses dados corroboram os achados de Brito (1999) e Neiva-Silva (2003) que assinalam a droga como um fator de risco para o desenvolvimento. Quando associado à situação de rua potencializa o risco, deixando ainda mais vulneráveis as pessoas atingidas. A fala da menina C. R., de 15 anos, retrata o uso cotidiano das drogas na rua: "Eu só peço dinheiro e gasto em droga, maconha, loló,... e fumo cigarro. Desde os sete anos... Claro, eu sou viciada daí eu gosto, gosto mais de cheirar loló. Quando meus amigos têm, assim, eles me dão. Daí quando eu tenho dinheiro eu compro mais loló e cigarro".

$\mathrm{O}$ uso de drogas por meninos e meninas em situação de rua é bastante complexo e ocorre por diversos motivos, tais como acompanhar os amigos, fazer parte do grupo, curiosidade, diversão, amenizar a fome e o frio, esquecer a tristeza, entre outros. Essa diversidade relacionada às motivações para o uso de drogas também foi encontrada no estudo de Neiva-Silva (2003). A fala da menina C. A. de 15 anos: "Eu uso drogas... porque eu ficava triste e aí eu chorava... e aí eu ficava... e quando eu usava eu ficava feliz!!!" apresenta o uso da droga como uma "poção mágica" capaz de amenizar o sofrimento, afastar a sensação de abandono e angústia, além de promover uma sensação imensa de prazer, "protegendo-o" da condição perversa em que se encontra. No entanto, essa fantasia da proteção proporciona, muitas vezes, uma maior exposição ao risco, como pode ser observado no relato do menino G. L., de 15 anos: "Faz seis anos que eu tô na rua, eu fugi, já usava loló. Fiquei morando na rua, quatro anos, fui roubado na rua, estava chapado... um dia roubei, foi um arrombamento, estava muito louco, mas os guarda nos pegaram, apanhamos muito... E olha, quase fui atropelado! Ali na frente da rodoviária, estava cheirando loló assim, e um guri estava na minha frente assim... na rua. Eu estava escrevendo no meio da rua, dai ele pulou para calçada e eu me assustei e vi um caminhão, daí eu fui para a calçada. Bah, se eu ficasse ali o caminhão ia passar e me amassar. Bah, pensei! Bah, matrix consegui, meu, me salvar".

Esses adolescentes apontam inúmeras justificativas e motivações para o consumo dessas substâncias, além disso, podem ser apontados como facilitadores a disponibilidade e o fácil acesso que essa população possui para conseguir suas drogas. A perda e a modifica- 
ção de referenciais familiares, culturais e, até, históricos têm sido indicados como fatores determinantes para que esses jovens se sintam cada vez mais solitários e desamparados frente às exigências oriundas do meio social e familiar (Noto \& Silva, 2002).

Todos os eventos relatados trazem à tona problemáticas freqüentes na população que vive no ambiente da rua, tais como a violência nelas e nas casas que abandonaram ou das quais foram excluídos, a participação em gangues ou grupos que se utilizam da violência para realizar ou alcançar algum objetivo, e o uso de drogas. Esses são os fatores de risco mais presentes na trajetória de rua e ressaltam a escassez dos fatores de proteção e da rede de apoio social para os mesmos. Dessa forma, propiciam a emergência dos diferentes papéis durante episódios de vitimização. As próprias crianças e adolescentes em situação de rua os identificam em seu cotidiano: "Assim ó, quando eu preciso, eu sou violento mesmo, já agredi um monte de gente... Não sei, acho que preciso sobreviver, nem que para isso eu tenha que me meter num rolo, tipo assalto, crime, sei lá... às vezes, eu acho que não merecia estar aqui, não pedi para nascer, só queria ter uma vida normal, ter uma casa, uma família... muito ruim estar em um lugar onde as pessoas não gostam da gente, na minha casa, meu pai não gostava de mim, só do meu irmão, acho que ele achava que não era meu pai de verdade, sabe... ele me disse uma vez, eu chorei muito... era pequeno. Minha mãe não fez nada, ele me batia muito, não gostava de mim, nem da minha mãe, batia muito nela também, eu via tudo e só chorava... queria que as coisas fossem diferentes...".

Os resultados demonstram a influência que a cultura, a sociedade e ausência de vínculos estáveis com a família exercem na assunção dos diferentes papéis envolvidos no processo de vitimização. A escassez de uma rede de apoio social efetiva e de cuidadores potencializa o impacto que a violência assume na vida das crianças e adolescentes em situação de rua. Ser o agressor, a vítima ou a testemunha de um episódio de violência é fato corriqueiro na vida diária desses, seja referente à necessidade de sobrevivência ou à ação marginal. Através da análise dos relatos, podemos constatar que muitos jovens atuam de forma desfavorável frente ao próprio desenvolvimento. A vivência de risco, a descrença, os preconceitos e estereótipos presentes na sociedade comprometem a percepção e o reconhecimento de si como pessoas em desenvolvimento e cristalizam a imagem contraditória "coitadinhos ou delinqüentes". Ambas perpetuam situações sociais marginais. É urgente perceber que essas meninas e meninos são atuantes no seu desenvolvimento, mesmo em risco. É importante e necessário compreender a vivência da rua na sua interação entre risco e saúde. As experiências, os papéis e as habilidades desenvolvidas nesse contexto devem ser valorizadas e analisadas em sua totalidade. No entanto, a rua continua sendo um ambiente de risco e potencialmente inadequado para o desenvolvimento de qualquer ser humano.

\section{REFERÊNCIAS}

Almeida, A. \& Del Barrio, C. (2002). A vitimização entre companheiros em contextos escolares. Um instrumento narrativo para estudo das representações dos maus-tratos na pré-adolescência: o scan bullying. Em Machado, C. \& Abrunhosa, R. (Coords). Violência e Vitimas de Crimes. Vol. II: Criança, Cap. 5, pp. 169-197. Coimbra: Quarteto.

Alves, P. B. (1998). O brinquedo e as atividades cotidianas de crianças em situação de rua. Dissertação de Mestrado não publicada, Curso de Pós-graduação em Psicologia do Desenvolvimento, Universidade Federal do Rio Grande do Sul, Porto Alegre, RS.

Alves, P. B. (2002). Infância, tempo e atividades cotidianas das crianças em situação de rua: as contribuições da teoria dos sistemas ecológicos. Tese de Doutorado não publicada, Curso de Pós-graduação em Psicologia do Desenvolvimento, Universidade Federal do Rio Grande do Sul, Porto Alegre, RS.

Aneci Rosa, C. S., Borba, R. E. S. R. \& Ebrahim, G. J. (1992). The street children of Recife: a study of their background. Journal of Tropical Pediatries, 38, 34-40.

Aptekar, L. (1996). Crianças de rua nos países em desenvolvimento: uma revisão de suas condições. Psicologia Reflexão $e$ Crítica, 9, 153-184.

Bandeira, D., Koller, S. H., Hutz, C. \& Forster, L. (1996). O cotidiano dos meninos de rua de Porto Alegre. Anais do XVII Internacional School Psychology Congress, Tomo II (pp. 133134). Campinas, São Paulo.

Bardin, L. (1979). Análise de conteúdo. (L. A. Reto \& A. Pinheiro, Trad.). São Paulo: Edições 70/Livraria Martins Fontes.

Brito, R. C., Barros, J., Keisner, B., Oliveira, E. A., Porciúncula, L., Richter, E. \& Koller, S. H. (1998). Tentativa de suicídio entre meninos e meninas em situação de rua em Porto Alegre. Em II Congresso Nacional de Psicologia do Desenvolvimento, Gramado, RS.

Brito, R. C. (1999). Uso de drogas entre meninos e meninas em situação de rua: subsídios para uma intervenção comunitária. Dissertação de Mestrado não publicada, Curso de Pós-graduação em Psicologia do Desenvolvimento, Universidade Federal do Rio Grande do Sul, Porto Alegre, RS.

Bronfenbrenner, U. (1996). A ecologia do desenvolvimento humano: experimentos naturais e planejados. Porto Alegre: Artes Médicas. (Originalmente publicado em 1979).

Bronfenbrenner, U. \& Morris, P. (1998). The ecology of developmental processes. In W. Damon (Org.), Handbook of child psychology, Vol. I (pp. 993-1027). New York: Jonh Wiley \& Sons.

Campos, R., Raffaelli, M., Ude, W., Greco, M., Ruff, A., Rolf, J., Antunes, C. M., Halsey, N. \& Greco, D. (1994). Social networks and daily activities of street youth in Belo Horizonte, Brazil. Child Development, 65, 319-330.

Carlini, E. A. (1990). Research is badly needed to improve programmes for the prevention and treatment of drug abuse dependence in Brazil. Special Issue: Research and policy. Drug and alcohol dependence, 25, 169-173.

Carpena, M. (1999). Famílias de meninos e meninas em situação de rua na cidade de Caxias do Sul: locus de controle, situação 
atual de vida e expectativas para o futuro. Dissertação de Mestrado não publicada, Curso de Pós-graduação em Psicologia do Desenvolvimento, Universidade Federal do Rio Grande do Sul, Porto Alegr, RS.

Cecconello, A. \& Koller, S. H. (2003). Inserção ecológica na comunidade: uma proposta metodológica para o estudo de famílias em situação de risco. Psicologia: Reflexão e Crítica, 23, $1-14$.

Cerqueira-Santos, E. (2004). Um estudo sobre a brincadeira das crianças em situação de rua. Dissertação de Mestrado não publicada, Curso de Pós-graduação em Psicologia do Desenvolvimento, Universidade Federal do Rio Grande do Sul, Porto Alegre, RS.

Conselho Federal de Psicologia. (2000). Resolução 016, Brasília, Distrito Federal.

De Antoni, C. \& Koller, S. H. (2002). Violência doméstica e comunitária. Em M. L. J. Contini, S. H. Koller \& M. N. S. Barros (Orgs), Adolescência e psicologia: Concepções, práticas e reflexões críticas (pp. 85-91). Brasília: Conselho Federal de Psicologia.

Estatuto da Criança e do Adolescente (1990). 13.07.1990. São Paulo: Cortez.

Forster, L. M. K., Barros, H. M. T., Tannhauser, S. L. \& Tannhauser, M. (1992). Meninos na rua: relação entre abuso de drogas e atividades ilícitas. Revista da ABP-APAL, 14, 115-120.

Garbarino, J., Kostelny, K. \& Dubrow, N. (1991). What children can tell us about living in danger. American Psychologist, 46, 376-383.

Hodges, E., Boivin, M., Vitaro, F. \& Bukowiski, N. M. (1999). The power of friendishp: friendship as the factor in the cycle of victimization and maladjustment. Developmental Psychology, 35, 94-101.

Hutz, C. S. \& Koller, S. H. (1996). Questões sobre o desenvolvimento de crianças em situação de rua. Estudos em Psicologia, 2, 175-197.

Hutz, C. S. \& Koller, S. H. (1999). Methodological and ethical issues in research with street children. Em M. Raffaelli \& R.W. Larson (Orgs.), Homeless and working youth around the world: exploring developmental issues. New Directions for Child and Adolescent Development (pp. 59-70). São Francisco, CA: Jossey-Bass.

Koller, S. H. (1994). Julgamento moral pró-social de meninos e meninas de rua. Tese de Doutorado. Curso de Pós-graduação em Educação, Pontifícia Universidade Católica do Rio Grande do Sul, Porto Alegre, RS.

Koller, S. H. (1999). Violência doméstica: uma visão ecológica. Em AMENCAR (Org), Violência doméstica (pp. 32-42). Brasília: Unicef.

Koller, S. H. \& De Antoni, C. (2004).Violência Intrafamiliar: Uma Visão Ecológica. Em S. H. Koller (Org.), Ecologia do desenvolvimento humano: pesquisa e intervenção no Brasil (pp. 293-310). Porto Alegre: Casa do Psicólogo.

Koller, S. H. \& Hutz, C. S. (1996). Meninos e meninas em situação de rua: dinâmica, diversidade e definição. Coletâneas da ANPEPP: Aplicações da Psicologia na Melhoria da Qualidade de Vida, 1, 11-34.
Martins, R. A. (1996). Censo de crianças e adolescentes em situação de rua em São José do Rio Preto. Psicologia Reflexão $e$ Crítica, 9, 101-122.

Neiva-Silva, L. (2003). Expectativas futuras de adolescentes em situação de rua: um estudo autofotográfico. Dissertação de Mestrado não publicada, Curso de Pós-graduação em Psicologia do Desenvolvimento, Universidade Federal do Rio Grande do Sul, Porto Alegre, RS.

Neiva-Silva, L. \& Koller, S. H. (2002). A rua como contexto de desenvolvimento. Em E. R. Lordelo, A. M. A. Carvalho \& S. H. Koller (Orgs.), Infância brasileira e contextos de desenvolvimento (pp. 202-230). São Paulo, SP: Casa do Psicólogo, Salvador, BA: Editora da Universidade Federal da Bahia.

Noto, A. R., Galduróz, J. C. F., Nappo, S. A., Fonseca, A., Carlini, C., Moura, Y. \& Carlini, E. (2003). Levantamento nacional sobre o uso de drogas entre crianças e adolescentes em situação de rua nas 27 capitais brasileiras - 2003. Centro de Informações sobre Drogas Psicotrópicas - CEBRID. Universidade Federal de São Paulo - Escola Paulista de Medicina.

Noto, A. R. \& Silva, E. (2002). Em M. L. J. Contini, S. H. Koller \& M. N. S. Barros (Orgs.), Adolescência e psicologia: concepções, práticas e reflexões críticas (pp. 85-91). Brasília: Conselho Federal de Psicologia.

Paludo, S. (2004). Expressão das emoções morais de crianças em situação de rua. Dissertação de Mestrado não publicada, Curso de Pós-graduação em Psicologia do Desenvolvimento, Universidade Federal do Rio Grande do Sul, Porto Alegre, RS.

Paludo, S. \& Koller, S. (2004). Inserção ecológica no contexto da rua. Em S. H. Koller (Org.), Ecologia do Desenvolvimento Humano: Pesquisa e intervenção no Brasil (pp. 219-244). Porto Alegre: Casa do Psicólogo.

Raffaeli, M., Koller, S. H., Reppold, C. T., Kuschick, M. B., Krum, F. M. B. \& Bandeira, D. R. (2000). How do Brazilian street youth experience 'the street'? Analysis of a sentence completion task. Childhood, 8, 396-415.

Salmivalli, C., Lagerspetz, R., Bjoerkqvist, K., Oesterman, K. \& Kauklainen, A. (1996). Bullying as a group process: participant roles and their relations to social status within the group. Aggressive Behavior, 22, 1-15.

Santana, J. (2003). Instituições de atendimento à crianças em situação de rua: a relação entre os objetivos e significados atribuídos por seus dirigentes e pelas crianças atendidas. Dissertação de Mestrado não publicada, Curso de Pós-graduação em Psicologia do Desenvolvimento, Universidade Federal do Rio Grande do Sul, Porto Alegre, RS.

Swart-Kruger, J. \& Donald, D. (1996). Crianças das ruas da África do Sul. Psicologia: Reflexão e Crítica, 9, 59-82.

Verma, S. (1999). Socialization for survival: developmental issues among working street children in India. Em M. Raffaelli \& R.W. Larson (Orgs.), Homeless and working youth around the world: Exploring developmental issues. New Directions for Child and Adolescent Development (pp. 5-18). São Francisco, CA: Jossey-Bass.

Enviado: 20/11/2004 Revisado: $15 / 02 / 2005$ Aceito: $10 / 03 / 2005$ 


\section{Notas:}

1 Apoio Capes.

2 As autoras agradecem a participação das bolsistas de Inicicação Científica do Grupo de Estudos sobre emoções morais e desenvolvimento em situação de risco do CEP-RUA/UFRGS.

3 Este estudo faz parte da Dissertação de Mestrado em Psicologia do Desenvolvimento (UFRGS) da primeira autora, orientada pela segunda autora.

\section{Sobre as autoras:}

Simone Paludo: Psicóloga, Doutoranda e Mestre em Psicologia do Desenvolvimento do Curso de Pós-Graduação em Psicologia do Desenvolvimento da Universidade Federal do Rio Grande do Sul. Membro do Centro de Estudos Psicológicos sobre Meninos e Meninas de Rua (CEP-RUA/UFRGS). Coordenadora da Equipe de Pesquisa sobre Emoções morais e desenvolvimento em situação de risco do CEP-RUA/UFRGS. Endereço eletrônico: cep_rua@ufrgs.br.

Silvia Helena Koller: Psicóloga, Doutora em Educação (PUCRS), Pesquisadora CNPq e Professora do Curso de Pós-Graduação em Psicologia do Desenvolvimento da Universidade Federal do Rio Grande do Sul. Coordenadora do Centro de Estudos Psicológicos sobre Meninos e Meninas de Rua (CEP-RUA/UFRGS).

Endereço para corespondência: Universidade Federal do Rio Grande do Sul. Endereço para correspondência: CEP-RUA/UFRGS, Instituto de Psicologia, Rua Ramiro Barcelos 2600/104, CEP: 90035-003, Porto Alegre, RS. Fone: (51) 33165150, Fax (51) 32410074. 
